\title{
Cylindrocladiella peruviana and Pleiocarpon algeriense causing stem and crown rot on avocado (Persea americana)
}

\author{
Dalia Aiello • Giorgio Gusella • Alessandro Vitale • \\ Vladimiro Guarnaccia • Giancarlo Polizzi
}

Accepted: 21 July 2020 / Published online: 2 August 2020

(C) The Author(s) 2020

\begin{abstract}
During the winter of 2018, 3-years-old trees of avocado (Persea americana) cv "Hass" from Trapani province (Sicily, Italy) showed symptoms of stem and crown rot. Two different fungi were consistently isolated from infected tissues. Morphological characterization and multi-locus phylogenies using five genomic loci (ITS, tef1, tub2, his3, and rpb2) identified these fungi as Cylindrocladiella peruviana and Pleiocarpon algeriense. Pathogenicity tests on healthy 5-monthsold seedlings and 3-year-old trees of avocado reproduced similar symptoms as those observed in nature, and Koch's postulates were fulfilled for both pathogens. Moreover, the tested fungal isolates revealed a different pathogenic behaviour among two species. Two isolates of Pleiocarpon algeriense resulted more aggressive than Cylindrocladiella peruviana isolates causing major lesions on young seedlings. This study is the first to report of stem and crown rot on avocado caused by Cylindrocladiella peruviana and Pleiocarpon algeriense.
\end{abstract}

D. Aiello $(\bowtie) \cdot$ G. Gusella $\cdot$ A. Vitale $\cdot$ G. Polizzi

Dipartimento di Agricoltura, Alimentazione e Ambiente, sezione Patologia Vegetale, University of Catania, Via S. Sofia 100, 95123 Catania, Italy

e-mail: dalia.aiello@unict.it

V. Guarnaccia

DiSAFA, University of Torino, Largo Paolo Braccini, 2, 10095 Grugliasco, TO, Italy
Keywords Fungal diseases $\cdot$ Nectriaceae $\cdot$ Molecular characterization

\section{Introduction}

Avocado (Persea americana Mill.) is native to Mexico but is spread around the world in tropical and subtropical regions. In southern Italy (Sicily), several farms of different extension coexist, directing their production to local market as well as European market (Migliore et al. 2018). Although the agronomic studies on this crop in Italy started more than 20 years ago, studies on phytopathological aspects have been limited. Recently, a wide study on branch cankers and stem-end rot conducted in the main avocado growing area in eastern Sicily revealed the presence of different species such as Neofusicoccum parvum (the highest virulent), Diaporthe foeniculina (=D. foeniculaceae), D. sterilis, Colletotrichum gloeosporioides, C. fructicola, and a novel species Neocosmospora perseae (Guarnaccia et al. 2016, 2018). These reports show how woody cankers and stem-end rot could be considered the most important threats for avocado production in Italy so far.

Avocado symptoms at the rhizosphere such as rot, discolouration, sunken lesions, and subsequent aspecific symptoms of the canopy such as wilt, leaves chlorosis/ browning, and decline, have been studied worldwide. These studies showed how several species within the Nectriaceae (Hypocreales, Ascomycetes) are involved in what is defined "Black root rot disease" (Dann et al. 2011, 2012; Parkinson et al. 2017a, b). A recent research 
conducted in Australia demonstrated that several Dactylonectria spp. and C. ilicicola are pathogenic to avocado, compared to other isolates of Ilyonectria sp., Cylindrocladiella pseudoinfestans and Gliocladiopsis peggii that did not result pathogenic (Parkinson et al. 2017b). Several reports also include the species Ilyonectria destructans (often with previous binomial denomination) associated with black root rot of avocado (Besoain and Piontelli 1999; Zilberstein et al. 2007; Ramírez-Gil and Morales-Osorio 2013) and Ilyonectria macrodidyma (Vitale et al. 2012). However, due to the numerous taxonomic changes and limited pathogenicity tests, Ilyonectria spp. were considered not pathogenic to this crop (Parkinson et al. 2017b), although species of this genus are well known as pathogen to many other plants (Úrbez-Torres et al. 2012; Lombard et al. 2013; Aiello et al. 2014, 2015). Among Cylindrocladiella species, C. parva has been found on roots and cuttings of avocado in South Africa (Crous et al. 1991) and associated with the dead 3-year-old avocado plants in Australia (Dann et al. 2012) and C. pseudoinfestans was collected from symptomatic avocado trees cultivated in nursery although theirs pathogenicity was not demonstrated (Parkinson et al. 2017b). C. peruviana, has been previously reported associated with root decay and cutting rot symptoms, but no data are available about its pathogenicity (Crous 2002; Van Coller et al. 2005). Root rot caused by the oomycete Phytophthora cinnamomi, and collar rot caused by $P$. citricola have been considered for decades the most important root diseases in avocado orchards (Erwin and Ribeiro 1996).

Recently in Italy, young avocado trees showing symptoms of stem and crown rot were observed and brought to our laboratory for further investigations. The aim of the present study is to identify the fungal species associated with those symptoms and to evaluate their ability to induce symptoms on seedlings and young trees of avocado.

\section{Materials and methods}

Field sampling, isolations and morphological characterization

During the autumn of 2018, 20 young 3-year-old trees of avocado cv "Hass" from Campobello di Mazara, Trapani province (Sicily, Italy) were sampled, and analyses have been conducted in the laboratory. All the samples showed symptoms of stem and crown rot. Occasionally, as a consequence of severe infection, root rot was also observed. Small sections of basal stem and crown tissue were surface disinfected for $1 \mathrm{~min}$ in $1.5 \%$ sodium hypochlorite $(\mathrm{NaOCl})$, rinsed in sterile distilled water, dried on sterile absorbent paper, and placed on potato dextrose agar (PDA, Oxoid, Basingstoke, UK) amended with $100 \mathrm{mg} / \mathrm{l}$ of streptomycin sulfate (SigmaAldrich, USA) to prevent bacterial growth, and then incubated at $25 \pm 1{ }^{\circ} \mathrm{C}$ for 5-7 days. Single-conidial cultures were transferred on synthetic nutrient-poor agar (SNA; Nirenburg 1981) for morphological characterization. The morphological characteristics were determined with 30 measurements at $\times 1000$ magnification of conidia mounted in lactic acid.

Molecular characterization and phylogenetic analysis

Genomic DNA was extracted from fourteen isolates (Table 1) using the Wizard Genomic DNA Purification Kit (Promega Corporation, WI, USA). Species identification was achieved through DNA amplification and sequencing of a combined data set of loci: the nuclear ribosomal internal transcribed spacer (ITS) region, partial regions of the $\beta$-tubulin (tub2), the translation elongation factor- $1 \alpha$ (tefl), the histone $\mathrm{H} 3$ (his 3 ) and the RNA polymerase II second largest subunit (rpb2) genes. The primers used were ITS5 and ITS4 (White et al. 1990), T1 and Bt-2b (O'Donnell and Cigelnik 1997), EF1-728F and EF1-986R (Carbone and Kohn 1999), CYLH3F and CYLH3R (Crous et al. 2004), RPB2-5F2 and RPB2-7cR (O'Donnell et al. 2007), respectively. The PCR amplification mixtures and cycling conditions were adopted for the two loci were followed as described by Guarnaccia and Crous (2018) and Aigoun-Mouhous et al. (2019). Both strands of the PCR products were sequenced by Eurofins Genomics Service (Ebersberg, Germany). The generated DNA sequences were analyzed and consensus sequences were computed using the Geneious v. 11.1.5 software (Auckland, New Zealand).

Novel sequences obtained in this study were blasted using the NCBIs GenBank nucleotide database, to identify the most similar relatives for a taxonomic framework of the studied isolates. Alignments of different gene regions, including sequences obtained from this study and those downloaded from GenBank, were initially performed by using the MAFFT v. 7 online server 
(http://mafft.cbrc.jp/alignment/server/index.html) (Katoh and Standley 2013), and then manually adjusted in MEGA v. 7 (Kumar et al. 2016).

Phylogenetic analyses were conducted for establishing the identity of the isolates at species level, first individually for each locus (data not shown) and then as combined analyses of five loci. Additional reference sequences were selected based on recent literature of Nectriaceae species (Polizzi et al. 2012, Aiello et al. 2014, Lombard et al. 2015, Aigoun-Mouhous et al. 2019, Marin-Felix et al. 2019a, b). Phylogenetic analyses were based on Maximum Parsimony (MP) for the individual loci and on MP and Bayesian Inference (BI) for the multi-locus analyses. Related with BI, the best evolutionary model for each partition was determined using MrModeltest v. 2.3 (Nylander 2004) and incorporated into the analysis. MrBayes v. 3.2.5 (Ronquist et al. 2012) was used to generate phylogenetic trees under optimal criteria per partition. The Markov Chain Monte Carlo (MCMC) analysis used four chains and started from a random tree topology. The heating parameter was set to 0.2 , and trees were sampled every 1000 generations. Analyses stopped at the moment which the average standard deviation of split frequencies was below 0.01. The MP analyses were conducted using PAUP (Phylogenetic Analysis Using Parsimony, v. 4.0b10; Swofford 2003). Phylogenetic relationships were estimated by heuristic searches with 100 random addition sequences. Tree bisection-reconnection was used, with the branch swapping option set on 'best trees' only with all characters weighted equally and alignment gaps treated as missing data. Tree length (TL), consistency index (CI), retention index (RI) and rescaled consistence index (RC) were calculated for parsimony and bootstrap analyses (Hillis and Bull 1993), which were based on 1000 replications. Sequences generated in this study are deposited in GenBank (Table 1).

Pathogenicity and virulence on seedlings of avocado

Pathogenicity assays with two fungal species (Pleiocarpon algeriense and Cylindrocladiella peruviana) isolated from the avocado samples were performed to fulfil Koch's postulates. Simultaneously, the decay amounts (symptom severities on basal stem and crown as measure of relative virulence) associated to each fungal isolate were evaluated and compared using young seedlings and avocado plants. Four type isolates were selected from the sample subset of isolates comprising two strains of Pleiocarpon algeriense, Di3A-AP26 and Di3A-AP50, and two isolates of Cylindrocladiella peruviana, Di3A-AP41 and Di3A-AP39. Pathogenicity of these isolates was assayed on healthy, 5-months-old seedlings of avocado. In detail, 12 inoculated plants for each fungal isolate were arranged in a randomized complete block design (RCBD) with three replicates, each consisting of four inoculated seedlings. To this aim, a piece of bark was removed at the base of the stem with a $6 \mathrm{~mm}$ diameter cork-borer and 6-mm-diameter mycelial plugs taken from a 12-day-old fungal colony were applied as previously reported (Aiello et al. 2014, 2015, 2017). The wounds were covered with Parafilm to prevent desiccation. Controls consisted of sterile PDA plugs applied similarly to healthy young 12 seedlings. All avocado plants were kept in a growth chamber, with a $12 \mathrm{~h}$ photoperiod at $25^{\circ} \mathrm{C} \pm 1{ }^{\circ} \mathrm{C}$ and regularly watered. Disease incidence (DI, percentage of symptomatic plants), symptom severity (as lesion length - SSL) of the resulting lesions was recorded 2 months after inoculation. Re-isolations were performed for seedlings to confirm their pathogenicity. The experiments were performed twice.

Pathogenicity and virulence on young trees of avocado

Two isolates (Di3A-AP50 and Di3A-AP39) were inoculated onto 18 healthy 3 -years-old avocado trees according to a randomized complete block design with three replicates, each consisting of three young trees. In detail, a piece of bark was removed at the base of the stem using a $7.5 \mathrm{~mm}$ diameter cork-borer and a mycelial plug of equal size taken from a 12-day-old fungal colony was applied. Controls consisted of sterile PDA plugs applied to nine healthy young trees. All avocado plants were kept in a growth chamber, with a $12 \mathrm{~h}$ photoperiod at $25^{\circ} \mathrm{C} \pm 1{ }^{\circ} \mathrm{C}$ and regularly watered. Disease incidence (DI, percentage of symptomatic plants) and symptom severity (as lesion length - SSL, and lesion depth - SSD expressed in $\mathrm{mm}$ ) of the resulting lesions were recorded four months after the inoculations. Re-isolations were performed from artificially infected avocado trees to confirm their pathogenicity. The experiments were performed twice.

Data analysis

Data concerning virulence of Pleiocarpon algeriense and Cylindrocladiella peruviana isolates on avocado 
Table 1 Codes and GenBank accession numbers for isolates included in this study

\begin{tabular}{|c|c|c|c|c|c|c|}
\hline \multirow[t]{2}{*}{ Species } & \multirow[t]{2}{*}{ Culture no. ${ }^{1}$} & \multicolumn{5}{|c|}{ GenBank no. ${ }^{2}$} \\
\hline & & ITS & tefl & tub2 & his & $r p b 2$ \\
\hline Calonectria ilicicola & CBS $190.50^{\mathrm{T}}$ & GQ280605 & AY725726 & AY725631 & AY725676 & KM232307 \\
\hline Cylindrocladiella addiensis & CBS $143794^{\mathrm{T}}$ & MH111383 & MH111393 & MH111388 & - & - \\
\hline Cy. australiensis & CBS $129567^{\mathrm{T}}$ & JN100624 & JN099060 & JN098747 & JN098932 & - \\
\hline Cy. brevistipitata & CBS $142786^{\mathrm{T}}$ & - & MF444940 & MF444926 & - & - \\
\hline Cy. camelliae & IMI 346845 & AF220952 & JN099087 & AY793471 & AY793509 & KM232304 \\
\hline Cy. clavata & CBS $129564^{\mathrm{T}}$ & JN099095 & JN098974 & JN098752 & JN098858 & - \\
\hline Cy. cymbiformis & CBS $129553^{\mathrm{T}}$ & JN099103 & JN098988 & JN098753 & JN098866 & - \\
\hline Cy. elegans & CBS $338.92^{\mathrm{T}}$ & AY793444 & JN099039 & AY793474 & AY793512 & - \\
\hline Cy. ellipsoidea & CBS $129573^{\mathrm{T}}$ & JN099094 & JN098973 & JN098757 & JN098857 & - \\
\hline Cy. hawaiiensis & CBS $129569^{\mathrm{T}}$ & JN100621 & JN099057 & JN098761 & JN098929 & - \\
\hline Cy. horticola & CBS $142784^{\mathrm{T}}$ & MF444911 & MF444938 & MF444924 & - & - \\
\hline Cy. humicola & CBS $142779^{T}$ & MF444906 & MF444933 & MF444919 & - & - \\
\hline Cy. infestans & CBS $111795^{\mathrm{T}}$ & AF220955 & JN099037 & AF320190 & AY793513 & - \\
\hline Cy. kurandica & CBS $129577^{\mathrm{T}}$ & JN100646 & JN099083 & JN098765 & JN098953 & - \\
\hline Cy. lageniformis & CBS $340.92^{\mathrm{T}}$ & AF220959 & JN099003 & AY793481 & AY793520 & KM232303 \\
\hline Cy. lanceolata & CBS $129566^{\mathrm{T}}$ & JN099099 & JN098978 & JN098789 & JN098862 & - \\
\hline Cy. lateralis & CBS $142788^{\mathrm{T}}$ & MF444914 & MF444942 & MF444928 & - & - \\
\hline Cy. longiphialidica & CBS $129557^{\mathrm{T}}$ & JN100585 & JN098966 & JN098790 & JN098851 & - \\
\hline Cy. longistipitata & CBS $116075^{\mathrm{T}}$ & AF220958 & JN098993 & AY793506 & AY793546 & - \\
\hline Cy. microcylindrica & CBS $111794^{\mathrm{T}}$ & AY793452 & JN099041 & AY793483 & AY793523 & - \\
\hline Cy. natalensis & CBS $114943^{T}$ & JN100588 & JN099016 & JN098794 & JN098895 & - \\
\hline Cy. nauliensis & CBS $143792^{\mathrm{T}}$ & MH111387 & MH111397 & MH111392 & - & - \\
\hline Cy. nederlandica & CBS $152.91^{\mathrm{T}}$ & JN100603 & JN099033 & JN098800 & JN098910 & - \\
\hline Cy. novazelandica & CBS $486.77^{\mathrm{T}}$ & AF220963 & JN099050 & AY793485 & AY793525 & - \\
\hline Cy. parva & CBS 114524 & AF220964 & JN099009 & AY793486 & AY793526 & \\
\hline \multirow[t]{8}{*}{ Cy. peruviana } & CBS 114953 & JN099123 & JN099006 & JN098805 & JN098885 & - \\
\hline & IMUR $1843^{\mathrm{T}}$ & AF220966 & JN098968 & AY793500 & AY793540 & - \\
\hline & Di3A-AP39 & MT613323 & MT510671 & MT510677 & MT635005 & MT634991 \\
\hline & Di3A-AP41 & MT613324 & MT510672 & MT510678 & MT635006 & MT634992 \\
\hline & Di3A-AP44 & MT613325 & MT510673 & MT510679 & MT635007 & MT634993 \\
\hline & Di3A-AP45 & MT613326 & MT510674 & MT510680 & MT635008 & MT634994 \\
\hline & Di3A-AP47 & MT613327 & MT510675 & MT510681 & MT635009 & MT634995 \\
\hline & Di3A-AP48 & MT613328 & MT510676 & MT510682 & MT635010 & MT634996 \\
\hline Cy. pseudocamelliae & CBS $129555^{\mathrm{T}}$ & JN100577 & JN098958 & JN098814 & JN098843 & - \\
\hline Cy. pseudohawaiiensis & CBS $210.94^{\mathrm{T}}$ & JN099128 & JN099012 & JN098819 & JN098890 & - \\
\hline Cy. pseudoinfestans & CBS $114531^{\mathrm{T}}$ & AF220957 & JN099004 & AY793508 & AY793548 & - \\
\hline Cy. pseudoparva & CBS129560 ${ }^{\mathrm{T}}$ & JN100620 & JN099056 & JN098824 & JN098927 & - \\
\hline Cy. queenslandica & CBS $129574^{\mathrm{T}}$ & JN099098 & JN098977 & JN098826 & JN098861 & - \\
\hline Cy. reginae & CBS $142782^{\mathrm{T}}$ & MF444909 & MF444936 & MF444922 & - & - \\
\hline Cy. stellenboschensis & CBS $110668^{\mathrm{T}}$ & JN100615 & JN099051 & JN098829 & JN098922 & - \\
\hline Cy. terrestris & CBS $142789^{\mathrm{T}}$ & MF444915 & MF444943 & MF444929 & - & - \\
\hline Cy. thailandica & CBS $129571^{\mathrm{T}}$ & JN100582 & JN098963 & JN098834 & JN098848 & - \\
\hline Cy. variabilis & CBS $129561^{\mathrm{T}}$ & JN100643 & JN099080 & JN098719 & JN098950 & - \\
\hline
\end{tabular}


Table 1 (continued)

\begin{tabular}{|c|c|c|c|c|c|c|}
\hline \multirow[t]{2}{*}{ Species } & \multirow[t]{2}{*}{ Culture no. ${ }^{1}$} & \multicolumn{5}{|c|}{ GenBank no. ${ }^{2}$} \\
\hline & & ITS & tef1 & tub2 & his & $r p b 2$ \\
\hline Cy. viticola & CBS $112897^{\mathrm{T}}$ & AY793468 & JN099064 & AY793504 & AY793544 & - \\
\hline Cy. vitis & CBS $142517^{\mathrm{T}}$ & KY979751 & KY979891 & KY979918 & - & - \\
\hline Dactylonectria macrodidyma & CBS $112615^{\mathrm{T}}$ & AY677290 & JF268750 & AY677233 & JF735647 & JF268710 \\
\hline D. torresensis & CBS $129086^{\mathrm{T}}$ & JF735362 & JF735870 & JF735492 & JF735681 & KM232347 \\
\hline Ilyonectria capensis & CBS 132815 & JX231151 & JX231119 & JX231103 & JX231135 & KM232336 \\
\hline I. palmarum & CBS 135753 & HF937432 & HF922615 & HF922609 & HF922621 & - \\
\hline Neonectria ditissima & CBS 100316 & KM515890 & KM515944 & DQ789858 & - & DQ789787 \\
\hline \multirow[t]{9}{*}{ Pleiocarpon algeriense } & CBS $144964^{\mathrm{T}}$ & MH587320 & MH587323 & MH587324 & MH587296 & MH587322 \\
\hline & Di3A-AP26 & MT613330 & MT597130 & MT597138 & MT635011 & MT634997 \\
\hline & Di3A-AP27 & MT613331 & MT597131 & MT597139 & MT635012 & MT634998 \\
\hline & Di3A-AP28 & MT613332 & MT597132 & MT597140 & MT635013 & MT634999 \\
\hline & Di3A-AP29 & MT613333 & MT597133 & MT597141 & MT635014 & MT635000 \\
\hline & Di3A-AP31 & MT613334 & MT597134 & MT597142 & MT635015 & MT635001 \\
\hline & Di3A-AP50 & MT613335 & MT597135 & MT597143 & MT635016 & MT635002 \\
\hline & Di3A-AP51 & MT613336 & MT597136 & MT597144 & MT635017 & MT635003 \\
\hline & Di3A-AP52 & MT613337 & MT597137 & MT597145 & MT635018 & MT635004 \\
\hline P. livistonae & CBS $145030^{\mathrm{T}}$ & MK539963 & MK540165 & MK540179 & MK540234 & MK540095 \\
\hline \multirow[t]{3}{*}{ P. strelitziae } & CBS $142251^{\mathrm{T}}$ & KY304644 & KY304722 & KY304750 & KY304616 & KY304697 \\
\hline & CBS 142252 & KY304663 & KY304741 & KY304769 & KY304635 & KY304713 \\
\hline & СРC 27629 & KY304645 & KY304723 & KY304751 & KY304617 & KY304698 \\
\hline Thyronectria quercicola & CBS $128976^{\mathrm{T}}$ & JF832624 & JF832581 & JF832880 & KM231595 & KM232411 \\
\hline Xenogliocladiopsis cypellocarpa & CBS $133814^{\mathrm{T}}$ & KM231760 & KM231885 & KM232017 & KM231479 & KM232332 \\
\hline
\end{tabular}

\footnotetext{
${ }^{1}$ CPC: Culture collection of P.W. Crous, housed at Westerdijk Fungal Biodiversity Institute; CBS: Westerdijk Fungal Biodiversity Institute, Utrecht, the Netherlands; Di3A: Dipartimento di Agricoltura, Alimentazione e Ambiente, Catania, Italy. IMI: International Mycological Institute, CABI-Bioscence, Egham, Bakeham Lane, U.K.; IMUR: Institute of Mycology, University of Recife, Recife, Brazil. Ex-type and ex-epitype cultures are indicated with ${ }^{\mathrm{T}}$

${ }^{2}$ ITS: the nuclear ribosomal internal transcribed spacer region; tef1: partial translation elongation factor 1- $\alpha$ gene; tub2: partial beta-tubulin gene; his: the histone $\mathrm{H} 3$ gene; $r p b 2$ : the RNA polymerase II second largest subunit gene. Sequences generated in this study are indicated in italics
}

plants cv 'Hass' from the repeated experiment were analysed by using the Statistica package software (version 10; Statsoft Inc., Tulsa, OK, USA). The arithmetic means of DI and SS values [expressed both as lesion length $\left(=\mathrm{SS}_{\mathrm{L}}\right)$ and as lesion depth $\left(=\mathrm{SS}_{\mathrm{D}}\right)$ ] were calculated averaging the values determined for each replicates of each treatment. Percentage DI data were transformed into the arcsine $\left(\sin ^{-1}\right.$ square root $\left.\mathrm{x}\right)$ prior to analysis of variance (ANOVA), whereas both SS values were not transformed. Initial analyses of DI and SS data were performed by calculating $\mathrm{F}$ and $P$ values associated to evaluate whether the effects of single factor (fungal isolate) and isolate $\times$ trial interactions are significant on single disease parameters. In the post-hoc analyses, the corresponding mean values of DI and SS were subsequently separated by the Fisher's least significance difference test $(\alpha=0.05)$. Untransformed arithmetic means of DI and SS are presented in the Tables 2 and 3.

\section{Results}

Field sampling, isolation and morphological characterization

A widespread wilting of avocado plants was observed in one orchard located in Campobello di Mazara (Trapani province) where approximately 2,200 plants were 
Table 2 Pathogenicity and compared virulence among Pleiocarpon algeriense and Cylindrocladiella peruviana isolates on avocado seedlings

\begin{tabular}{|c|c|c|}
\hline Isolate & DI $(\%)^{\mathrm{x}}$ & SS (lesion length $-\mathrm{mm})^{\mathrm{x}}$ \\
\hline Pleiocarpon algeriense Di3A-AP50 & 100 & $35.44 \pm 1.66 \mathrm{a}$ \\
\hline Pleiocarpon algeriense Di3-AP26 & 100 & $18.33 \pm 0.36 \mathrm{~b}$ \\
\hline Cylindrocladiella peruviana Di3A-AP41 & 100 & $12.18 \pm 0.69 \mathrm{c}$ \\
\hline \multirow[t]{2}{*}{ Cylindrocladiella peruviana Di3A-AP39 } & 100 & $13.3 \pm 0.99 \mathrm{c}$ \\
\hline & - & $\begin{array}{l}\mathrm{F}(\text { isolate })=224.945 ; P=0.000^{z} \\
\mathrm{~F}(\text { isol. } \times \text { trial })=0.012 ; P=0.998^{\mathrm{ns}}\end{array}$ \\
\hline
\end{tabular}

${ }^{\mathrm{x}}$ Data derived from two repeated experiments. Means are from three replicates (each consisting of four plants). \pm standard error of the mean (SEM); Values followed by the same letters within the column are not significantly different according to the Fisher's least significance differences test $(\alpha=0.05)$

${ }^{\mathrm{z}} \mathrm{F}$ test and associated $\mathrm{P}$ value of fixed effects; ns = not significant

cultivated. Disease incidence was approximately $40 \%$. Symptomatic plants showed symptoms of stem and crown rot and subsequent stunted growth, general wilting and leaf chlorosis. Moreover, basal stem and crown were dry, cracked and showed external decay and internal discolouration of tissues, which sometimes resulted in the detachment of the bark and/or of roots from the stem (Fig. 1). Occasionally, in an advanced stage of infection root rot was also observed. More of 800 plants were dead. Nectriaceae-like fungi colonies were consistently obtained from isolation of symptomatic tissues obtained from 20 plants and divided in two typologies depending on their appearance in culture. A total of 34 isolates were obtained from a single conidium or hyphal tip of pure cultures on PDA at $25^{\circ} \mathrm{C} \pm 1{ }^{\circ} \mathrm{C}$.

Based on the microscopic observations, the isolates of Cylindrocladiella peruviana produced conidia cylindrical, rounded at both ends, straight, 1-septate, 8 to $13 \times 2$ to $3 \mu \mathrm{m}$ in accordance with the description by AgustíBrisach et al. (2012). Pleiocarpon algeriense produced microconidia and macroconidia straight to curved, 1-5- septate, predominantly 3, 4-septate. Macroconidia 3septate were 41 to $48 \times 5$ to $7 \mu \mathrm{m}$ while conidia 4 septate measured 52 to $64 \times 7$ to $8 \mu \mathrm{m}$ in accordance with the description by Aigoun-Mouhous et al. (2019).

All the isolates were stored in the collection (label name Di3A-AP) of Dipartimento di Agricoltura, Alimentazione e Ambiente (Di3A), Catania, Italy. Moreover, two isolates of each typology were stored in the collection of Westerdijk Fungal Biodiversity Institute, Utrecht, The Netherlands.

Molecular characterization and phylogenetic analysis

Six alignments were analysed representing single gene analyses of ITS, tef1, tub2, his and $r p b 2$, and a combined alignment of the five genomic loci. The alignments provided topologically similar trees. The combined species phylogeny consisted of 65 sequences, including the sequences of Xenogliocladiopsis cypellocarpa (culture CBS 133814) as outgroup. A total of 3193 characters (ITS: 1-538, tef1: 545-1060, tub2: 1067-1782, his:

Table 3 Pathogenicity and compared virulence between Pleiocarpon algeriense and Cylindrocladiella peruviana isolates on avocado young trees

\begin{tabular}{llll}
\hline Isolate & $\mathrm{DI}(\%)^{\mathrm{x}}$ & $\mathrm{SS}_{\mathrm{L}}$ (lesion length, mm $)^{\mathrm{x}}$ & $\mathrm{SS}_{\mathrm{D}}(\text { lesion depth, mm })^{\mathrm{x}}$ \\
\hline Pleiocarpon algeriense Di3A-AP50 & 100 & $83.67 \pm 1.6 \mathrm{a}$ & $1.92 \pm 0.11 \mathrm{a}$ \\
Cylindrocladiella peruviana Di3A-AP39 & 100 & $15.67 \pm 0.09 \mathrm{~b}$ & $1.0 \pm 0.00 \mathrm{~b}$ \\
& - & $F($ isolate $)=3435.4 ; P=0.000^{z}$ & $\mathrm{~F}($ isolate $)=44.73 ; P=0.000^{z}$ \\
& & $\mathrm{~F}($ isol $\times$ trial $)=2.05 ; P=0.19^{\mathrm{ns}}$ & $\mathrm{F}($ isol $\times$ trial $)=0.24 ; P=0.64^{\mathrm{ns}}$ \\
\hline
\end{tabular}

\footnotetext{
${ }^{\mathrm{x}}$ Data derived from two repeated experiments. Means are from three replicates (each consisting of three plants). \pm standard error of the mean (SEM); Values followed by the same letters within the column are not significantly different according to the Fisher's least significance differences test $(\alpha=0.05)$

${ }^{\mathrm{z}} \mathrm{F}$ test and associated $P$ value of fixed effects; ns = not significant
} 

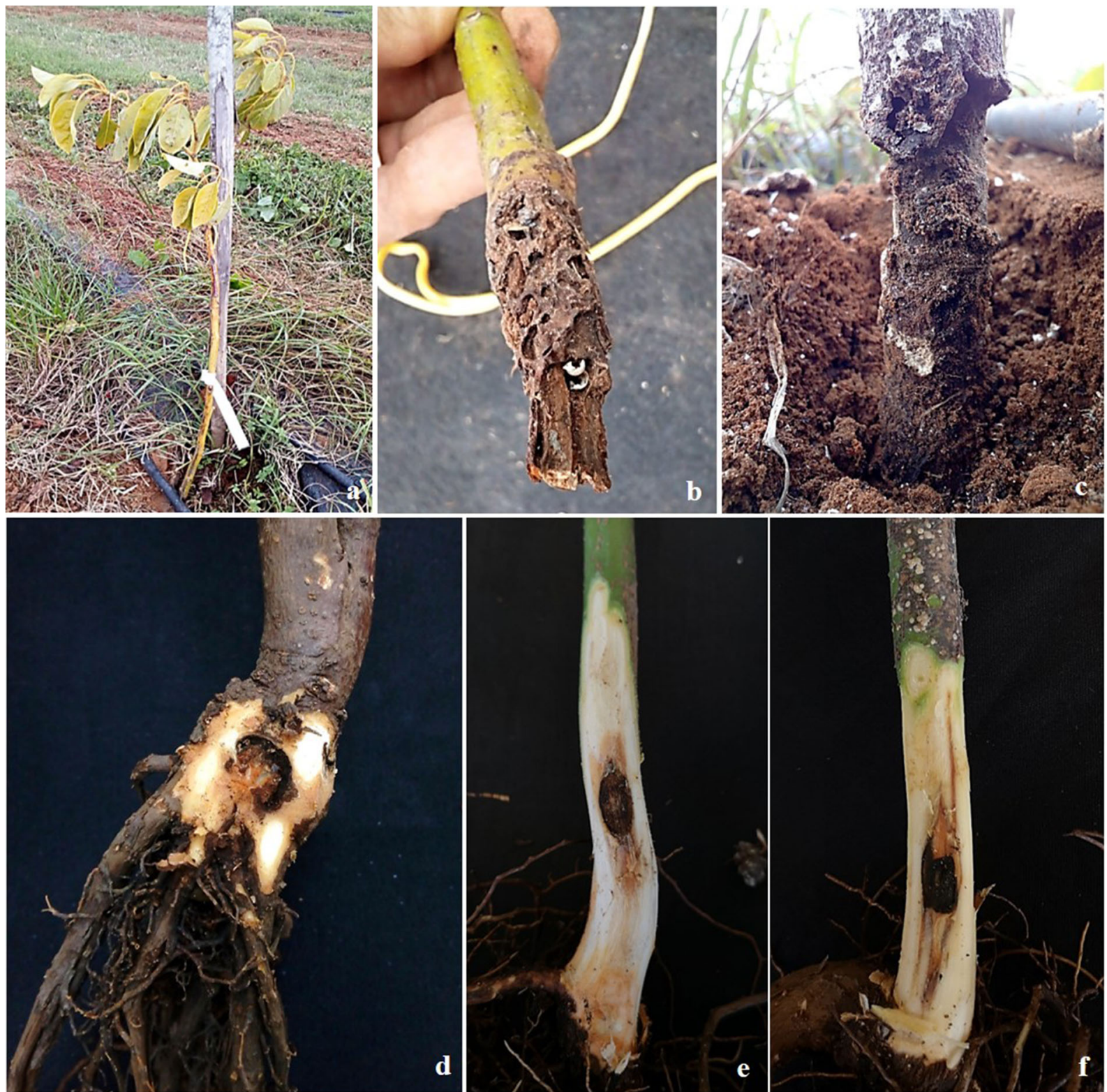

Fig. 1 Symptoms caused by Cylindrocladiella peruviana and Pleiocarpon algeriense on avocado plants. a stunted growth, wilting and leaf chlorosis; b, c, $\mathbf{d}$ stem and crown rot; $\mathbf{e}, \mathbf{f}$

1789-2333, rpb2: 2340-3193) were included in the phylogenetic analysis; 1245 characters were parsimony-informative, 383 were variable and parsimony-uninformative, and 1541 were constant. A maximum of 1000 equally most parsimonious trees were saved (Tree length $=5390, \mathrm{CI}=0.559, \mathrm{RI}=0.836$ and $\mathrm{RC}=0.467$ ). Bootstrap support values from the parsimony analysis are plotted on the Bayesian phylogenies in Fig. 2. For the Bayesian analyses, MrModeltest suggested that both the symptoms on artificially inoculated young trees with Cylindrocladiella peruviana (e) and Pleiocarpon algeriense (f)

partitions should be analysed with dirichlet state frequency distributions. The following models were recommended by MrModeltest and used: GTR $+\mathrm{I}+\mathrm{G}$ for ITS, tef1 and his, $\mathrm{HKY}+\mathrm{I}+\mathrm{G}$ for $t u b 2, \mathrm{SYM}+\mathrm{G}$ for $r p b 2$. In the Bayesian analysis, the ITS tef1, tub2, his and $r p b 2$ partitions had 210, 377, 443, 279 and 350 unique site patterns, respectively. The analysis ran for 4,770,000 generations, resulting in 4771 trees of which 3579 were used to calculate the posterior probabilities. 
Fig. 2 Consensus phylogram of 4771 trees resulting from a Bayesian analysis of the combined ITS, tef1, tub2, his and rpb2 sequences. Bayesian posterior probability and bootstrap support values are indicated at the nodes. Bold indicates ex-type strains. The tree was rooted to Xenogliocladiopsis cypellocarpa (CBS 133814)

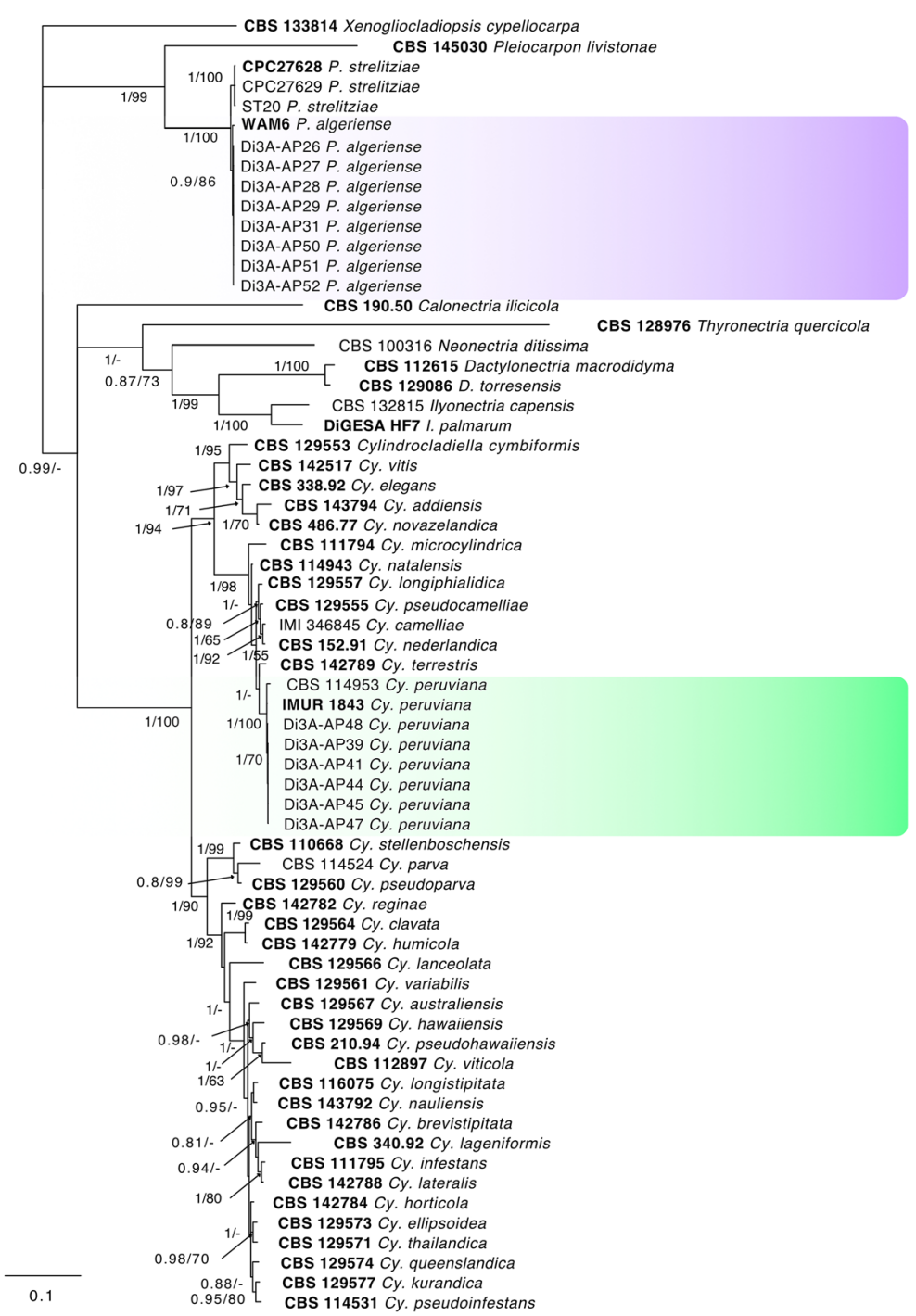

In the combined analysis, eight representative isolates from avocado roots clustered with the ex-type of $P$. algeriense. A further six isolates identified as C. peruviana, formed with two reference strains, a highly supported subclade (1.00/100) in the broad group of Cylindrocladiella spp. The individual alignments and trees of the five single loci used in the analyses were compared with respect to their performance in species recognition.

\section{Pathogenicity and virulence on avocado}

In in vivo experiments (both on seedlings and trees of avocado) a significant effect of fungal isolate was always detected on SS parameters $(P$ value $<0.0001)$ except for DI values since they were always $100 \%$. Since isolate $\times$ trial interactions were always not significant $(\mathrm{P}$ value $>0.6)$ for all detected SS parameters (Tables 2 and 3 ) the two trials regarding both avocado seedlings and young trees were combined and statistically analysed.

Pathogenicity and virulence on seedlings of avocado 2 months after artificial inoculation of both fungi, symptoms produced in seedlings were similar to those present in the orchard. These consisted of stem and crown rot. In correspondence to the inoculated site, above the bark was visible necrotic lesion which also extended under the bark (Fig. 3). No symptoms were observed on control plants. The pathogens were re-isolated from symptomatic tissues, thus fulfilling Koch's postulates. 


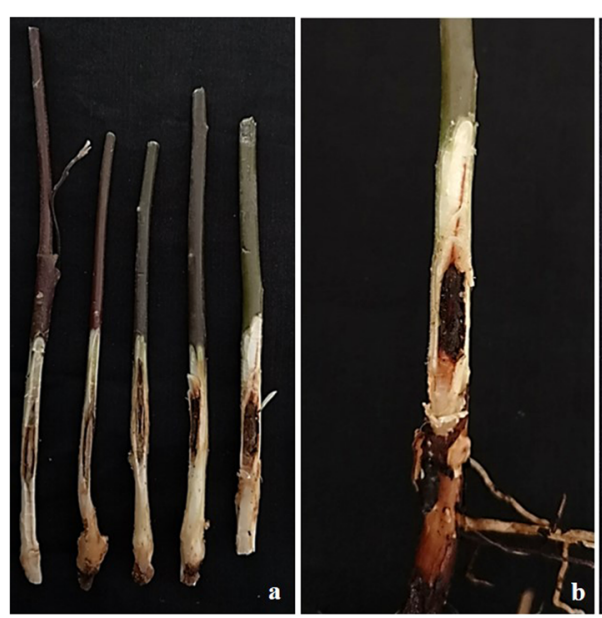

Fig. 3 Symptoms on artificially inoculated seedlings with Pleiocarpon algeriense and Cylindrocladiella peruviana. Internal necrotic lesions caused by Pleiocarpon algeriense $(\mathbf{a}, \mathbf{b})$ and

Regarding disease severities in the post-hoc analyses, the tested fungal isolates revealed a different pathogenic behaviour, resulting $P$. algeriense species more virulent than $C$. peruviana species. Moreover, $P$. algeriense Di3A-AP50 resulted the most aggressive isolate in inducing symptoms on avocado seedlings among all tested isolates (Table 2).

Four months after artificial inoculation of both fungi, symptoms produced in trees were similar to those present in the orchard. These consisted of necrotic lesions above the bark in correspondence to the inoculated site (Fig. 1). No symptoms were observed on control plants. The pathogens were re-isolated from symptomatic tissues, thus fulfilling Koch's postulates. As shown in Table 3, P. algeriense Di3A-AP50 caused always $\mathrm{SS}_{\mathrm{L}}$ and $\mathrm{SS}_{\mathrm{D}}$ values significantly higher than those recorded for C. peruviana Di3A-AP39 (Table 3).

\section{Discussion}

This study reveals for the first time the presence and pathogenicity of $C$. peruviana and $P$. algeriense on avocado. The polyphasic approach based on morphological and molecular analyses permitted to distinguish the collected strains at the species level within the broad genera of Cylindocladiella and Pleiocarpon.

Cylindrocladiella (Hypocreales, Nectriaceae) genus includes soil-borne fungi, often reported in several studies with the name of Cylindrocladium, lately

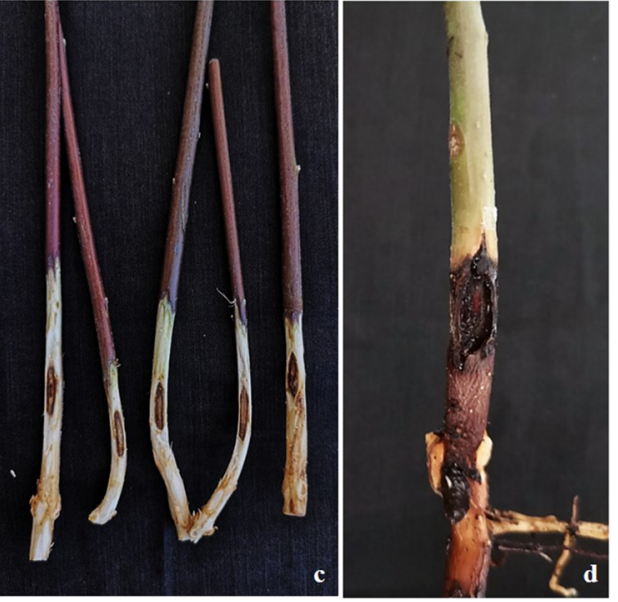

internal necrotic lesions and stem and crown rot caused by Cylindrocladiella peruviana $(\mathbf{c}, \mathbf{d})$

separated in two distinct genera, having Calonectria and Nectricladiella teleomorphs respectively (Boesewinkel 1982; Crous and Wingfield 1993; Crous et al. 1994; Schoch et al. 2000; Crous 2002). Cylindrocladiella spp. are frequently associated with root rot diseases of many plant species, e.g. on woody plants like Eucalyptus spp. and Pinus sp. (Boesewinkel 1986; Mohanan and Sharma 1985; Lombard et al. 2012). In Sicily, several studies have been conducted on crown and root rot of various plant hosts, revealing how species of the close genus Cylindrocladium (Calonectria) are widely spread across different hosts (Polizzi et al. 2007, 2012; Vitale et al. 2009, 2013). Different species of Cylindrocladiella including Cy. peruviana have been found on roots and cuttings of avocado. However, theirs pathogenicity has not been demonstrated on this crop (Darvas 1978; Crous et al. 1991; Van Coller et al. 2005; Dann et al. 2012; Parkinson et al. 2017b). Agustí-Brisach et al. (2012) reported Cy. peruviana for the first time in Spain associated with black-foot disease of grapevine, referring symptoms of reduced vigor, necrotic root lesions, and occasionally mortality. Similarly, Álvarez et al. (2012) in Perù and Koike et al. (2016) in California reported $C y$. peruviana and other Nectriaceae involved in blackfoot disease of grapevine. These recent reports, including the present study, confirm that this fungus plays a role in causing diseases, although Cylindrocladiella spp. are not typically considered 
primary pathogens (Lombard et al. 2012 ; Jayawardena et al. 2018).

Regarding the other nectriaceous species reported in this study, Aiello et al. (2017) described the new genus Pleiocarpon and P. strelitziae sp. nov. in Italy causing basal stem and root rot of the ornamental Strelitzia reginae. Pathogenicity tests demonstrated the aggressive pathogenic nature of $P$. strelitziae, resulting in mortality of all inoculated test plants within 2 months (Aiello et al. 2017). Recently, two new species of Pleiocarpon have been described; in particular P. livistonae from Livistona rotundifolia (Arecaceae) in Sri Lanka, causing root and corm rot (Marin-Felix et al. 2019a), and P. algeriense isolated in Algeria from grapevine cuttings with black-foot disease (AigounMouhous et al. 2019). Results of this studies demonstrated the pathogenicity of $C$. peruviana and $P$. algeriense on avocado. Moreover, the tested fungal isolates revealed a different pathogenic behaviour, resulting $P$. algeriense species more virulent than C. peruviana species. However, the symptoms observed in orchard could be the result of the interactions between different Nectriaceae species with different virulence levels as reported by some studies (Tewoldemedhin et al. 2011; Whitelaw-Weckert et al. 2013). Further evidences will be required to investigate the role of the single species involved in the disease and their interactions in pathogenesis. Prevention is the first strategy to manage these diseases. Affected plants produced in nursery could represent the primary way for nectriaceous spread through commercial orchards. Thus, the use of healthy plants and rapid fungi detection are crucial steps in prevention of stem and crown rot disease (Dann et al. 2012).

This study reports the presence and pathogenicity of two nectriaceous species on avocado in Italy for the first time, thereby the high risk of stem and crown rot in avocado commercial orchards. As described in this paper, $C y$. peruviana and $P$. algeriense isolates recovered from infected stem and crown tissue, were able to cause different symptom severity levels among them. Further studies should be addressed to establish the most effective strategies to prevent their spread from the nursery to the open field.

Acknowledgements This research was funded by Research Project 2016-2018 "Monitoraggio, caratterizzazione e controllo sostenibile di microrganismi e artropodi di interesse agrario" WP2 - 5A722192134.
Funding Information Open access funding provided by Università degli Studi di Catania within the CRUI-CARE Agreement. Authors also thank the grants which supported this work: 'Programma ricerca di Ateneo UNICT 2020-22 linea 2 and "STARTING GRANT 2020" - University of Catania (Italy).

\section{Compliance with ethical standards}

Conflict of interest The authors declare that they have no conflict of interest.

Open Access This article is licensed under a Creative Commons Attribution 4.0 International License, which permits use, sharing, adaptation, distribution and reproduction in any medium or format, as long as you give appropriate credit to the original author(s) and the source, provide a link to the Creative Commons licence, and indicate if changes were made. The images or other third party material in this article are included in the article's Creative Commons licence, unless indicated otherwise in a credit line to the material. If material is not included in the article's Creative Commons licence and your intended use is not permitted by statutory regulation or exceeds the permitted use, you will need to obtain permission directly from the copyright holder. To view a copy of this licence, visit http://creativecommons.org/licenses/by/4.0/.

\section{References}

Agustí-Brisach, C., Alaniz, S., Gramaje, D., Pérez-Sierra, A., Armengol, J., et al. (2012). First report of Cylindrocladiella parva and C. peruviana associated with black-foot disease of grapevine in Spain. Plant Disease, 96(9), 1381.

Aiello, D., Guarnaccia, V., Vitale, A., Cirvilleri, G., Granata, G., Epifani, F., Perrone, G., Polizzi, G., Groenewald, J. Z., \& Crous, P. W. (2014). Ilyonectria palmarum sp. nov. causing dry basal stem rot of Arecaceae. European Journal of Plant Pathology, 138(2), 347-359.

Aiello, D., Guarnaccia, V., Epifani, F., Perrone, G., \& Polizzi, G. (2015). 'Cylindrocarpon'and Ilyonectria species causing root and crown rot disease of potted Laurustinus plants in Italy. Journal of Phytopathology, 163(7-8), 675-680.

Aiello, D., Polizzi, G., Crous, P. W., \& Lombard, L. (2017). Pleiocarpon gen. nov. and a new species of Ilyonectria causing basal rot of Strelitzia reginae in Italy. IMA fungus, $8(1), 65-76$.

Aigoun-Mouhous, W., Elena, G., Cabral, A., Leon, M., Sabaou, N., et al. (2019). Characterization and pathogenicity of Cylindrocarpon-like asexual morphs associated with black foot disease in Algerian grapevine nurseries, with the description of Pleiocarpon algeriense sp. nov. European Journal of Plant Pathology, 154(4), 887-901.

Álvarez, L. A., Tamayo, D., Castilla, C., Munive, C., AgustíBrisach, C., et al. (2012). Occurrence of grapevine trunk pathogens in nurseries and vineyards in the northern and southern coast of Peru. Phytopathologia Mediterranea, 51, 425 . 
Besoain, X., \& Piontelli, E. (1999). Black root rot in avocado plants (Persea american Mill.) by Cylindrocarpon destructans: Pathogenicity and epidemiological aspects. Boletin Micologico, 14, 41-47.

Boesewinkel, H. J. (1982). Cylindrocladiella, a new genus to accommodate Cylindrocladium parvum and other smallspored species of Cylindrocladium. Canadian Journal of Botany, 60(11), 2288-2294.

Boesewinkel, H. J. (1986). New plant disease records from New Zealand. Australasian Plant Pathology, 15(1), 18-21.

Carbone, I., \& Kohn, L. M. (1999). A method for designing primer sets for speciation studies in filamentous ascomycetes. Mycologia, 91(3), 553-556.

Crous, P. W. (2002). Taxonomy and pathology of Cylindrocladium (Calonectria) and allied genera. St. Paul American Phytopathological Society.

Crous, P. W., \& Wingfield, M. J. (1993). A re-evaluation of Cylindrocladiella, and a comparison with morphologically similar genera. Mycological Research, 97(4), 433-448.

Crous, P. W., Phillips, A. J. L., \& Wingfield, M. J. (1991). The genera Cylindrocladium and Cylindrocladiella in South Africa, with special reference to forest nurseries. South African Forestry Journal, 157(1), 69-85.

Crous, P. W., Wingfield, M. J., \& Lennox, C. L. (1994). A comparison of generic concepts in Calonectria and Nectria with anamorphs in Cylindrocladium and Cylindrocladiella. South African Journal of Science, 90, 485-488.

Crous, P. W., Groenewald, J. Z., Risède, J. M., Simoneau, P., \& Hywel-Jones, N. (2004). Calonectria species and their Cylindrocladium anamorphs: Species with sphaeropedunculate vesicles. Studies in Mycology, 50, 415430.

Dann, E., Forsberg, L., Cooke, A., Pegg, K., Shivas, R., et al. (2011). The "Cylindro" complex of avocado root pathogens. In VII World Avocado Congress. Cairns, Australia: 1-12.

Dann, E. K., Cooke, A. W., Forsberg, L. I., Pegg, K. G., Tan, Y. P., \& Shivas, R. G. (2012). Pathogenicity studies in avocado with three nectriaceous fungi, Calonectria ilicicola. Gliocladiopsis sp. and Ilyonectria liriodendri. Plant Pathology, 61(5), 896-902.

Darvas, J. M. (1978). Common root pathogens from avocados. South African Avocado Growers Association Research Report, 2, 3-4.

Erwin, D. C., \& Ribeiro, O. K. (1996). Phytophthora disease worldwide. St. Paul: American Phytopathological Society.

Guarnaccia, V., \& Crous, P. W. (2018). Species of Diaporthe on Camellia and Citrus in the Azores Islands. Phytopathologia Mediterranea, 57, 307-319.

Guarnaccia, V., Vitale, A., Cirvilleri, G., Aiello, D., Susca, A., Epifani, F., Perrone, G., \& Polizzi, G. (2016). Characterisation and pathogenicity of fungal species associated with branch cankers and stem-end rot of avocado in Italy. European Journal of Plant Pathology, 146(4), 963976.

Guarnaccia, V., Sandoval-Denis, M., Aiello, D., Polizzi, G., \& Crous, P. W. (2018). Neocosmospora perseae sp. nov., causing trunk cankers on avocado in Italy. Fungal Systematics and Evolution, 1(1), 131-140.

Hillis, D. M., \& Bull, J. J. (1993). An empirical test of bootstrapping as a method for assessing confidence in phylogenetic analysis. Systematic Biology, 42, 182-192.
Jayawardena, R. S., Purahong, W., Zhang, W., Wubet, T., Li, X., Liu, M., Zhao, W., Hyde, K. D., Liu, J. H., \& Yan, J. (2018). Biodiversity of fungi on Vitis vinifera L. revealed by traditional and high-resolution culture-independent approaches. Fungal Diversity, 90(1), 1-84.

Katoh, K., \& Standley, D. M. (2013). MAFFT multiple sequence alignment software version 7: Improvements in performance and usability. Molecular Biology and Evolution, 30, 772780 .

Koike, S. T., Bettiga, L. J., Nguyen, T. T., \& Gubler, W. D. (2016). First report of Cylindrocladiella lageniformis and C. peruviana as grapevine pathogens in California. Plant Disease, 100(8), 1783.

Kumar, S., Stecher, G., \& Tamura, K. (2016). MEGA7: Molecular evolutionary genetics analysis version 7.0 for bigger data sets. Molecular Biology and Evolution, 33, 1870-1874.

Lombard, L., Shivas, R. G., To-Anun C, \& Crous, P. W. (2012). Phylogeny and taxonomy of the genus Cylindrocladiella. Mycological Progress, 11(4), 835-868.

Lombard, L., Bezuidenhout, C. M., \& Crous, P. W. (2013). Ilyonectria black foot rot associated with Proteaceae. Australasian Plant Pathology, 42(3), 337-349.

Lombard, L., Van der Merwe, N. A., Groenewald, J. Z., \& Crous, P. W. (2015). Generic concepts in Nectriaceae. Studies in Mycology, 80, 189-245.

Marin-Felix, Y., Hernández-Restrepo, M., Iturrieta-González, I., García, D., Gené, J., Groenewald, J. Z., Cai, L., Chen, Q., Quaedvlieg, W., Schumacher, R. K., Taylor, P. W. J., Ambers, C., Bonthond, G., Edwards, J., Krueger-Hadfield, S. A., Luangsa-ard, J. J., Morton, L., Moslemi, A., SandovalDenis, M., Tan, Y. P., Thangavel, R., Vaghefi, N., Cheewangkoon, R., \& Crous, P. W. (2019a). Genera of phytopathogenic fungi: GOPHY 3. Studies in Mycology, 94, 1-124.

Marin-Felix, Y., Hernández-Restrepo, M., Wingfield, M. J., Akulov, A., Carnegie, A. J., Cheewangkoon, R., Gramaje, D., Groenewald, J. Z., Guarnaccia, V., Halleen, F., Lombard, L., Luangsa-ard, J., Marincowitz, S., Moslemi, A., Mostert, L., Quaedvlieg, W., Schumacher, R. K., Spies, C. F. J., Thangavel, R., Taylor, P. W. J., Wilson, A. M., Wingfield, B. D., Wood, A. R., \& Crous, P. W. (2019b). Genera of phytopathogenic fungi: GOPHY2. Studies in Mycology, 92, 47-133.

Migliore, G., Farina, V., Guccione, G. D., \& Schifani, G. (2018). Quality determinants of avocado fruit consumption in Italy. Implications for small farms. Calitatea, 19(163), 148-153.

Mohanan, C., \& Sharma, J. K. (1985). Cylindrocladium causing seedling diseases of Eucalyptus in Kerala, India. Transactions of the British Mycological Society, 84(3), 538-539.

Nirenburg, H. I. (1981). A simplified method to identify Fusarium spp. Occurring on wheat. Canadian Journal of Botany, 59, 1599-1609.

Nylander, J. A. A. (2004). MrModeltest V 2. Programme distributed by the author. Evolutionary Biology Centre: Uppsala University, Uppsala.

O'Donnell, K., \& Cigelnik, E. (1997). Two divergent intragenomic rDNA ITS2 types within a monophyletic lineage of the fungus Fusarium are nonorthologous. Molecular Phylogenetics and Evolution, 7, 103-116. 
O'Donnell, K., Sarver, B. A., Brandt, M., et al. (2007). Phylogenetic diversity and microsphere array-based genotyping of human pathogenic Fusaria, including isolates from the multistate contact lens-associated U.S. keratitis outbreaks of 2005 and 2006. Journal of Clinical Microbiology, 45, 22352248.

Parkinson, L. E., Shivas, R. G., \& Dann, E. K. (2017a). Novel species of Gliocladiopsis (Nectriaceae, Hypocreales, Ascomycota) from avocado roots (Persea americana) in Australia. Mycoscience, 58(2), 95-102.

Parkinson, L. E., Shivas, R. G., \& Dann, E. K. (2017b). Pathogenicity of nectriaceous fungi on avocado in Australia. Phytopathology, 107(12), 1479-1485.

Polizzi, G., Vitale, A., Aiello, D., Dimartino, M. A., \& Parlavecchio, G. (2007). First report of damping-off and leaf spot caused by Cylindrocladium scoparium on different accessions of bottlebrush cuttings in Italy. Plant Disease, 91(6), 769.

Polizzi, G., Vitale, A., Aiello, D., Guarnaccia, V., Crous, P. W., \& Lombard, L. (2012). First report of Calonectria ilicicola causing a new disease on laurus (Laurus nobilis) in Europe. Journal of Phytopathology, 160, 41-44.

Ramírez-Gil, G., \& Morales-Osorio, J. G. (2013). First report of Cylindrocarpon destructans (Zinss) Scholten affecting avocado (Persea americana Mill.) seedling in Colombia. Revista de Protección Vegetal, 28(1), 27-35.

Ronquist, F., Teslenko, M., van der Mark, P., Ayres, D. L., Darling, A., Höhna, S., Larget, B., Liu, L., Suchard, M. A., \& Huelsenbeck, J. P. (2012). MrBayes 3.2: Efficient Bayesian phylogenetic inference and model choice across a large model space. Systematic Biology, 61, 539-542.

Schoch, C. L., Crous, P. W., Wingfield, M. J., \& Wingfield, B. D. (2000). Phylogeny of Calonectria and selected hypocrealean genera with cylindrical macroconidia. Studies in Mycology, $45,45-62$.

Swofford, D. L. (2003). PAUP*. Phylogenetic analysis using parsimony (*and other methods). Version 4.0b10. Sunderland: Sinauer Associates.

Tewoldemedhin, Y. T., Mazzola, M., Labuschagne, I., \& McLeod, A. (2011). A multi-phasic approach reveals that apple replant disease is caused by multiple biological agents, with some agents acting synergistically. Soil Biology and Biochemistry, 43(9), 1917-1927.

Úrbez-Torres, J. R., Peduto, F., \& Gubler, W. D. (2012). First report of Ilyonectria macrodidyma causing root rot of olive trees (Olea europaea) in California. Plant Disease, 96(9), 1378.

Van Coller, G. J., Denman, S., Groenewald, J. Z., Lamprecht, S. C., \& Crous, P. W. (2005). Characterisation and pathogenicity of Cylindrocladiella spp. associated with root and cutting rot symptoms of grapevines in nurseries. Australasian Plant Pathology, 34(4), 489-498.

Vitale, A., Aiello, D., Castello, I., Dimartino, M. A., Parlavecchio, G., \& Polizzi, G. (2009). Severe outbreak of crown rot and root rot caused by Cylindrocladium pauciramosum on strawberry tree in Italy. Plant Disease, 93(8), 842.

Vitale, A., Aiello, D., Guarnaccia, V., Perrone, G., Stea, G., \& Polizzi, G. (2012). First report of root rot caused by Ilyonectria (= Neonectria) macrodidyma on avocado (Persea americana) in Italy. Journal of Phytopathology, 160, 156-159.

Vitale, A., Crous, P. W., Lombard, L., \& Polizzi, G. (2013). Calonectria diseases on ornamental plants in Europe and the Mediterranean basin: An overview. Journal of Plant Pathology, 95(3), 463-476.

White, T. J., Bruns, T., Lee, S., \& Taylor, J. W. (1990). Amplification and direct sequencing of fungal ribosomal RNA genes for phylogenetics. In M. A. Innis, D. H. Gelfand, J. J. Sninsky, \& T. J. White (Eds.), PCR protocols: A guide to methods and applications: 315-322. San Diego, California: Academic Press.

Whitelaw-Weckert, M. A., Rahman, L., Appleby, L. M., Hall, A., Clark, A. C., Waite, H., \& Hardie, W. J. (2013). Co-infection by Botryosphaeriaceae and Ilyonectria spp. fungi during propagation causes decline of young grafted grapevines. Plant Pathology, 62(6), 1226-1237.

Zilberstein, M., Noy, M., Levy, E., Elkind, G., Zeidan, M., et al. (2007). Wilting disease of young avocado trees caused by Neonectria radicicola in Israel. In 6th world avocado congress (pp. 25-30). Chile: Viña Del Mar. 